physiological effects of the enkephalins. The somewhat enhanced in vitro and in vivo potency of kelatorphan compared with bestatin plus thiorphan also suggests an additional role for the dipeptidylaminopeptidase for which kelatorphan has a very high affinity ${ }^{6.7}$. In this regard, the use of tritiated inhibitors will be a useful way to locate the three enzymes in the central nervous system. Using autoradiography, enkephalinase is found in areas high in both enkephalin levels and mu- and delta-receptor binding sites, such as the striatum, periaqueductal grey matter, substantia nigra and spinal cord ${ }^{11}$. What these inhibitors do not reveal is whether the increased availability of the enkephalins results from either a pool of tonically released peptide or peptide released as a result of a particular stimulus.

The potential of this approach to the production of physiological analgesia is high, particularly because effects mediated by the delta (enkephalin-preferring) opiate receptor may produce less of the problematical side-effects of the mupreferring agonist morphine ${ }^{4}$. Furthermore, the results from animal studies discussed above indicate that the more inte- grated measures of nociception may be altered by the inhibition of enkephalin degradation, whereas reflex tests seem, in general, to be insensitive. On the other hand, there is no reason to believe that the effects of the enkephalins are simple and enhancement of their synaptic availability and actions may result in tolerance, dependence, receptor changes and other compensatory mechanisms, leading to long-term changes in neuronal excitability $^{12}$.

\footnotetext{
Roques, B.P. et al. in Spinal Opioids and the Relief of Pain 87 (eds Besson, 3.M. \& Lazorthes, Y.) (INSERM, Paris. 1985)

2. Giros. B et al in Spinal Opioids and the Relief of Pain leds Besson, J.M. \& Lazorthes, Y. 57 (INSERM, Paris, 1985)

3. Dua. A.. Pinsky, C. \& LaBella. F. Life Sci. 37, 985 (1985)

4. Kosterlitz. H. Proc. R. Soc. B225, 27 (1985).

. Waksman, G. et al. Eur. J. Pharm. 117, 233 (1985).

Fournie-Zaluski. M.C. et al. Eur. J. Pharmac. 102, 525 (1984)

7. Fournie-Zaluski, M.C. et al. J. med. Chem. 28, 1158 (1985)

Guilbaud, G. el al. Life Sci. 33, (1985)

9. Villaneuva, L. et al. Brain Res. 333, 156 (1985)

0. Mendlsohn, L., Johnason. B., Scott. W. \& Frederickson R.C. J. pharmac. exp. Theor. 234, (1985)

Waksman. G. et al. Proc. natn. Acad. Sci. (in the press) 12. Woolf, C.J. \& Wall. P.D. Nature 306, 739 (1983)
}

A.H. Dickenson is in the Department of Phar macology, University College London, Gower Street, London WCIE 6BT, UK.

\title{
Ecology
}

\section{The evolution of anti-predatory behaviour in zooplankton}

\author{
from Felicity A. Huntingford and Neil B. Metcalfe
}

Although we often take it for granted that behaviour has evolved in response to natural selection, most of the evidence for this is indirect and circumstantial, involving deduction from the distribution of behavioural variants in modern forms. However, an article on page 746 of this issue ${ }^{1}$ describes the rapid evolution of diurnal migration in zooplankton in response to stocking of lakes with fish and thus provides a notable exception.

One of the anti-predator responses of several vertebrate and invertebrate species $^{2-4}$ is that of predator-induced shifts in feeding habitat, whereby animals accept a reduced rate of food intake to avoid predation. The diurnal vertical migrations which are such a conspicuous feature of the behaviour of certain zooplankton species (ref. 5; see figure) could well reflect similar selection pressures ${ }^{\circ}$. Food resources are often more abundant in the upper water layers but, because of higher light levels, risk of predation by visually hunting planktivorous fish is also greater. During the day, the cost of increased predation outweighs the benefits of high rates of food intake and plankton migrate into deeper, safer but less productive water. This behaviour is most marked in species and age classes that are particularly vulnerable to predation. ${ }^{5.6}$. Some cases of predator-induced changes in feeding site involve short-term, reversible behavioural adaptations to variable local conditions in animals with relatively advanced behavioural capacities. The vertical migration in zooplankton, however, is more likely to be a genetically preprogrammed behavioural change.

Gliwicz's data come from studies of the day- and night-time distributions of juveniles of an annual copepod species (Cyclops abyssorum) in a series of isolated lakes in the Tatra mountains of Central Europe. Some of these lakes contain long-standing populations of planktivorous fish, others are free of such fish and yet others have been artificially stocked, mainly within the past 25 years. Vertical migration only occurs in those lakes that contain planktivorous fish and this behaviour is more marked in lakes with long-established fish populations than in recently stocked lakes.

The lakes differ in other respects, such as visibility and depth, and so although compelling, these results still provide only circumstantial support for the so-called predation hypothesis. But Gliwicz's study provides another, uniquely valuable, kind of evidence, in the form of data on the migratory patterns of $C$. abyssorum in one particular shallow lake at several different stages in a programme of stocking with planktivorous fish.

Twelve years after stocking began in this lake there was little evidence of diurnal migration, but now, some 23 years later, the plankton show strong migration away from the water surface during the day, burrowing into the substrate. The fact that migration only appeared after the plankton had been exposed to predation for several generations suggests that this is not a short-term, phenotypic response to the presence of predators. The rapid appearance (in evolutionary terms) of the migratory response is ascribed to the fact that, even in lakes with no predators, some individuals show small diurnal movements, so that right from the start material was available for natural selection to work on.

Thus Gliwicz has tracked the gradual evolution of migratory behaviour in response to an artificially imposed increase in predation pressure. His study sheds light on the way natural selection moulds antipredator responses, and so is comparable with the classic work on the occurrence of light and dark forms of the peppered moth (Biston betularia) which showed how the relative frequency of morphological variants change in response to a change in predation risk.

\footnotetext{
. Gliwicz. M.Z. Nature 320, 746 (1986)

Sih, A. Ecology' 63, 786 (1982)

. Stein. R.A. \& Magnuson, J.J. F.cology 57, 751 (1976).

. Werner. E.E. Gilliam. J.F. Hall. D.I. \& Mittelbach. G.G. Ecologv 64, 1540 (1983)

2. Zaret. T.M. \& Suffern. J.S. Limnol. Oceanogr. 21. 80t (1976)

6. Stein. R.A. in Predatcr-Prev Systems in Fisheries Manage ment (eds Stroud. R.H. \& Clepper. H.) 343 (Sport Fishing Institute. Washington DC).
}

Felicity A. Huntingford and Neil B. Metcalfe are in the Department of Zoology. University of Glasgow, Glasgow G128QQ, UK. 